\section{Improving Technical Assistance in Range Management in Developing Countries ${ }^{1}$}

ROALD A. PETERSON

Chief, Pasture and Fodder Crops Branch FAO, Rome, Italy

\section{Highlight}

Improving technical assistance in range management abroad requires a consistent orientation which takes fully into account major obstacles in lesser developed countries. It demands participation of technicians well qualified to analyse and deal with problems at various levels.

Probably the greatest single problem facing mankind is the imbalance between food supplies and actual needs for human health and vigor. Application of public health and medical knowledge has freed population growth from former controls. Ignorance, poverty, age-old customs, the basic environments and other factors prevent a corresponding growth in food supply. Meanwhile, peoples in developing countries, awakening to the hope of a better life, are no longer passive to hunger. This fact has changed the time dimension of the problem to one of urgency, the implications of which have not been well understood by either developed or developing countries. The urgency to increase animal protein production is particularly compelling.

By the year 2,000 the world's population is expected to double. If these six billion inhabitants are to have an adequate diet the lesser developed regions of the world will need from four to six times the amount of edible animal products they now consume, according to FAO's Third World Food Survey. Meeting this goal will require an annual increase of six to ten percent in production. Inasmuch as the present

\footnotetext{
1 Paper presented at the Annual Meeting, American Society of Range Management, Wichita, Kansas, February 10-14, 1964.
}

annual increase in edible animal produce is rarely more and often less than two or three percent (according to the 1962 FAO Production Yearbook), it is evident that intelligent, concerted action is essential to even approximate requirements.

Meeting the animal protein requirements will depend to no small extent upon better use of that one-fifth of the world's land surface which we call the rangelands. As pressure for food increases, one can expect that more of these lands will be plowed, and that many arable lands now being used for grazing will be restricted to crop production. Improvements in veterinary assistance and such developments as watering points and emergency feeding, when not combined with control of animal numbers, increase average grazing pressure. The decrease in available range, and the tendency for animal numbers to increase, plus rising demand for animal products, pose the problems with which range managers must grapple. Because time is short, better approaches and methods of work than those used in the past must be devised.

International technical assistance, especially U.S. AID, has pioneered the introduction of range management into the lesser developed countries. Considering that this has been done in less than two decades, it is no mean feat. Nevertheless, what has been accomplished to date is not commensurate with the needs nor equal to expectations raised by the results of range management in the USA. Certainly there are too few places in the lesser developed countries where one can point to greater stability and higher range production, and improved watershed conditions achieved through the application of range management. There is every reason to believe, however, that better results can be achieved. It is our purpose here to explore some of the ways in which this might be done.

Admittedly, it is harder to improve the management of rangelands than to improve many other aspects of agriculture, and the results are slower and not so easy to demonstrate. This does not, however, justify the view that efforts to improve and stabilize forage supply should be limited to the cultivated lands. With increasing competition for arable lands such a policy seems still less realistic, even though integration of livestock and crop agriculture offers good possibilities and should be encouraged in many areas. It must be recognized that in most of the lesser developed countries the great bulk of the grazing comes from native grasslands and will continue to do so in the foreseeable future. The question is how can we progress more effectively towards securing increased and more stable yields from these lands in the future, and more immediately, stop deterioration.

\section{Major Obstacles}

There are certain characteristics generally applicable to lesser-developed countries which have an over-riding influence on what should, and what can, be done. Failure to take these characteristics sufficiently into account helps to explain the lack of impact of many range management programs in the past.

Lack of basic data.-Improvement of grazing management requires certain minimum information often lacking or deficient in newly developing countries. These include knowledge of the composition and distribution of major range types, growth rate and phenology of important forage species, and the relative degree of utilization by animal 
species by seasons and in relation to various degrees of hunger stress. Information on the physical environment, while scattered and inadequately interpreted, can usually be obtained in sufficient detail to permit useful deductions. Few data are available on the influence of grazing treatment on the vegetation and on the responses of animals to current management and to the nutritional and physical environments. Lack of basic data impedes the work of range specialists and, especially in short assignments, frequently leads to failure-prone attempts to apply practices developed elsewhere without being adapted to the local milieu.

Dispersion of effort.-Lack of continuity and consistency in programs, priorities and personnel makes much of the work ineffective. These deficiencies grow out of such factors as lack of clear-cut, realistic goals, competition for human and financial resources, failure to define the relative worthwhileness of alternative programs, lack of experience, and political instability. Foreign experts too may add to the dispcrsion by giving contradictory advice. On the positive side is the fact that irrespective of the various factors tending to produce a dispersion of effort, the basic problems inherent in the production process in any given environment are relatively constant. Therefore, if these basic problems are well understood and clearly defined and programs laid out accordingly, dispersion of effort can steadily be reduccd. This aspect is discussed further under "Analysis of Problems."

Deeply ingrained social and cultural customs and patterns.-Modern agriculture is characterized by flexibility and capacity to adopt new techniques as conditions demand. Livestock production in the lesser developed countries, on the contrary, is usually bound by fixed patterns. The extreme case is ownership for numbers rather than production, for reasons of prestige or religion. Most commonly, the old patterns persist due to lack of market incentives, inadequate financial resources, including credits, and other negative factors. Ways of handling the animals and grazing systems associated with a historic way of life are not readily changed. Nomadism is a case in point. Its persistence is reinforced by its admirable adaptation to the utilization of a harsh and variable environment. However, the subsistence grazing practiced by most nomads is not adequate to present-day needs. Ways of changing and improving the system must be found. It is first necessary to understand the system as a whole and in detail in order to know its specific advantages and weaknesses. Separation and even hostility, which often prevails between graziers and crop farmers, contribute to the perpetuation of outmoded practices, and make difficult the development of alternative sources of feed, stratification of livestock, fattening, etc., which are essential for the best use of the range.

Shortage of skilled manpower. Available skilled manpower limits what can be done at a given moment. Often the few people trained in range management are put into administrative posts, or other jobs given higher priority but not directly related to their specialization. Even where a country's economy is strongly dependent upon grazing of native ranges one rarely finds more than two or three individuals actively working in the field. Animal husbandry specialists and ecologists are also deplorably few. While more training is needed, as widely recognized by the countries, it is clear that the first step is close collaboration among the few individuals available in related fields. Deficiency of skilled manpower is accentuated by the lack of adequate contact among those few working in the field. Without the stimulus from such contact, stagnation and resignation are ever-present dangers.

Deficiency of organization.-Considering the shortage of skilled manpower and relative isolation, it is not surprising that appropriate organizational channels are usually weak or non-existent. Further, those organizations which exist are rarely capable of dealing with the whole problem. For example, it is not uncommon to find that the unit responsible for the development of watering points is completely independent of that dealing with grazing management or vegetation survey. Under these circumstances, water development is frequently a handicap rather than an aid in the management of the range. In other instances, the only range unit is within the Forest Organization. There it may be little more than vestigial, even when grazing is the most important use of the forest. Impact from technical assistance cannot be expected to be great if there is no adequate organization to serve as a vehicle of continuity.

Research organizations for the study of range and pasture problems suffer from understaffing and lack of orientation towards the basic problems. Organization for research has been retarded by the oft-expressed view that the lesser developed countries should put their limited resources into application of "what is already known." This position ignores the fact that principles pertinent to given environments may be transferred but the combinations of materials (forage value of species, plant/animal inter-relationships, growth period, etc.) vary so much that many critical studies are inevitably needed. Nor does the position against research take into consideration its essential role in the development of skilled manpower and competent leadership. Fortunately, most developing countries are more and more appreciating their need for research and that research needs to be linked closely to practical problems and extension activities.

A chronic shortage of financial resources. - Governments, tribes, villages and individuals are characteristically short of finances. In the competition for available capital, range management receives a disproportionately small part of the total. Growth in international credits through the World Bank and other sources is a hopeful trend. The result is an increasing need for technicians to provide the technical basis upon which credit may be extended, and to advise how to make significant improvements with minimum expenditure.

Nor can the question of financial resources be separated from the need to improve all aspccts of marketing, stabilize prices within reasonable limits, work out better land tenure systems, etc. Not the least of financial needs is that of improving salaries for national technicians. 
terns of the land or other basis for control, lack of administrative responsibility and failure on the part of the government authorities to appreciate the importance of the range resource, are other obstacles that will often beset the range manager.

\section{Analysis Of Problems}

In view of the obstacles, making effective advances in range management requires some unifying guide to relate the pertinent aspects of the problem into a meaningful whole without restricting flexibility of action. This guide should permit the assignment of priorities, show the action required to overcome the various obstacles and give direction, continuity, and constancy to all programs relating to production from grazing lands.

Ideally, general problems and goals should first be defined and the relative importance of various programs indicated through an economic analysis. Detailed pre-investment surveys are useful to indicate the most convenient action locally. Ecological studies are of great value to provide estimates of the potential of the resource, given the introduction of certain improvements, and for clarifying certain critical relationships concerning the environment and the vegetation.

It is also necessary to analyze and relate all the major factors which go into the production of animal products. These include: the environmental factors controlling the vegetation, the major characteristics of the vegetation and their variation spatially and in time, degree and time of utilization, efficiency of utilization and conversion to the marketable product, etc. Account must be taken of the practices used in animal management such as breeding, weaning and culling. The aim is to describe and identify the major sources of losses in the production process to be able to suggest where corrections can most feasibly be made.

The analysis should not be restricted to the native grazing lands, although these lands would normally be the focus of the problem. Other aspects of feeding and management which could influence the output of the country or an area as a whole should be included. For ex- ample, grazing on range is normally deficient during certain times of the year, especially for young and lactating animals. It is necessary to know the alternative sources of feed to reduce losses and increase output from the range. This might require improving yields of food crops on the better lands so that more of the marginal croplands could be sown down to pasture. It might also require adjusting charges for use of the range to encourage the production of cultivated forage crops. Better use of agricultural by-products can be a useful means for increasing animal production and reducing the pressure on the range.

Once this overall analysis has been made, detailed analyses of the range itself may be needed to set priorities of action.

In no case should it be supposed that all the desirable data must be available before a meaningful analysis can bc made. A surprising number of deductions can be made if the scattered information available, or readily acquired, is properly related.

The analyses must draw upon available local knowledge and involve the participation of the people directly concerned, so as to increase the possibilities of unified action. Very little of this has been done in the past, and it is in my opinion a major reason why range management technical assistance has so often not had a significant carryover effect.

Some feel that "the problems are already known, so why go through such an analysis." I insist, however, that the problems are known only in a most superficial sense and not in operational terms. How else can one explain, for example, that in developing countries comparisons are common between rotation (classical type, with rest between grazings of about 30 days) and continuous stocking? This, although rotation grazing may be expected to have little economic benefit and be difficult to apply. In these same places substantial increases may often be achieved by solving critical aspects of the grazing problem. A similar lack of understanding of the problem is illustrated by the development of expensive waterspreading devices in places where runoff is negligible, or where no ef- fective control over the flocks can be expected.

Clearly, understanding of the problems is the backbone of any program. Along with analysis of problems, other programs-experts, training courses, meetings, publications, etc.-should help make certain that: basic facts are gathered, dispersion of efforts is reduced, traditional behavior is taken into account, scarce manpower is effectively used, and economic factors are properly considered.

\section{Application Of Concepts}

The program of the Pasture and Fodder Crops Branch in the Plant Production and Protection Division of FAO tries to take into account the various obstacles discussed, and I should like to mention some of the ways in which this is done.

Field Officers-Individual experts are supplied to countries upon request within a quota under the Expanded Program of Technical Assistance, or under the UN Special Fund, or trust funds set up by individual countries. There are now about 35 field officers and this number is rising steadily. Most of them deal directly or indirectly with range problems, although less than a third are designated as range management specialists. In addition to their specific terms of reference, they are encouraged to: make an analysis of the problems so as to provide guidance for their own and future programs; assist in the development and orientation of research so that basic data needed for action programs will be made available; promote cooperation among national specialists dealing with various phases of animal production; assist in the development of an organization to deal with range management and other aspects of forage production; and carry out inservice and other forms of training. Countries are normally encouraged to keep the expert for at least three years in order to give him time to develop a pro- 
gram and assure some measure of continuity.

Stress is placed on the applicability of the expert's recommendations and whenever possible follow-up for implementation is provided.

Meetings.-The Branch has a working party on range, pasture and fodder development in each of three regions-Tropical America, the Mediterranean and the Near East. Similar working parties will eventually be organized in the Far East and in Africa south of the Sahara. Meetings are held every two to four years. These provide a forum for the discussion and definition of grazing and forage production problems, with emphasis on: ecological and geographical features; setting of priorities to concentrate efforts, make more efficient use of limited manpower, and assure continuity of programs; appraisal of social and economic features influencing range management and other phases of forage production and utilization; organization of cooperative undertakings such as studies of forage value, exchange of plant materials, etc.; and presentation of current research.

Close collaboration is maintained with the Animal Production and Health and other Divisions of FAO in meetings and other undertakings of common interest in order to stimulate the broader cooperation of all concerned with animal production.

Collection and Correlation of Basic Data. - The basic parameters of forage production and utilization are considered as those set by the character of the vegetation in the context of the physical environment. Therefore much value is placed on ecological studies. Studies of the plant/ environment complex are related as much as possible to animal responses and requirements on the one hand, and the possibilities for cultivated agriculture on the other. In some regions the major emphasis is on the integration of pastures with crop agriculture and the development of cultivated pastures. One study in agroclimatology has been carried out in the Near East in cooperation with the World Meteorological Organization and the United Nations Educational, Scientific and Cultural Organization, and another is under way in Africa south of the Sahara. These help to define the conditions prevailing for plant growth and indicate the approximate potential. FAO Agricultural Study No. 49 on "The Grass Cover of Africa" and similar studies planned or under way in other regions help to clarify certain central characteristics of rather large regions. These efforts, along with those made by other Divisions of the Organization and by the countries themselves, are gradually giving us the climatic, ecological and agronomic facts needed to understand regional and local problems.

Publications. - The publications of the Branch are designed to help in the understanding of problems related to specified ecological conditions and to provide guidance on how these problems may be attacked. Under preparation are manuscripts on the management and improvement of semi-arid grazing lands; on utilization and improvement of tropical pastures in Central Africa; on the status of knowledge on grazing and pasture problems in East Africa; and a bibliography on studies of tropical pastures and native grasslands.

Other considerations. - While meetings improve interchange of ideas among technical workers, it is also necessary to increase the number of technicians in the field within each country and region. This is furthered through: training courses; exchange of communications; and grouping of Special Fund projects within a region so that visits may be facilitated among the technical personnel. For example, one UN Special Fund project on research is under way in Uruguay, and another has been approved for the provinces of Entre Rios and Corrientes in Argentina, just to the west of Uruguay. Work at these two projects will be coordinated and related to research being carried out in southern Brazil. Thirty or more technicians will be involved, all within about one day's drive of each other. This should provide a group large enough to give the strong stimulus so essential to sustained and creative effort.

More short courses are needed, as an effective means for developing common understanding, concerted action and an awakened public consciousness. In April and May of 1964 the Soviet Union sponsored a group fellowship course on grassland management and utilization in semiarid regions, under the Expanded Program of Technical Assistance. This provided an opportunity for studying the approach and methods used by the Russians on their semi-arid lands. Continuity of training and adequate follow-up of the students is needed in each major region. Funds, however, are hard to come by. One wonders if the Society of Range Management could not be instrumental in promoting such courses, perhaps in conjunction with the Freedom-from-Hunger Campaign.

We have made little progress in systematically relating implementation of practices to the various social-cultural systems. Let me refer again to the nomadic tribal system. Before rational progress towards improving this system can be made, we need to know the answer to such questions as: How effective is the nomadic system from the standpoint of utilization of the vegetation? Could utilization be im- 
proved with scientific evaluation of rainfall pattern and forage growth, enabling one to forecast forage availability in differrent areas? How can the cooperation of the nomads be secured? What kinds of changes could be most readily introduced into their system to improve productivity? At the FAO Conference (the governing body of FAO) last November, one of the delegates suggested that FAO and UNESCO should consider a joint project to study in depth the whole question of nomads. Very useful and widely applicable results could come from such a project.

Throughout our program we recognize that close cooperation is essential with all international and bilateral technical assistance agencies, in striving for the goal of properly feeding a proteinhungry world. Even with the best of collaboration, we may not succeed. Separately we will certainly fail.

A major difficulty is finding experts able to analyse and deal with problems at various levels. In this connection, American Universities, with their persistent drive towards specialization, do not foster the development of an individual who can see problems in terms of their inter-related parts. Range management training, while less at fault in this respect than training in most other fields, still needs, I believe, to place more emphasis on the focusing of the problems at different levels, and on the discovery of alternative and complementary solutions.

Another major difficulty is that not enough highly qualified individuals make themselves available for technical assistance work abroad. As members of the
American Society of Range Management, we should recognize that range management is in a sense on trial. Can it do the job demanded of it? Since joining FAO I have frequently heard doubt expressed that range management as practiced is adequate to the problems of the lesser developed countries. Certainly range management has not produced the results hoped for and I have tried to show how I think it might be more effective. There is need for this Society to actively encourage its best qualified members to take foreign assignments and facilitate their being able to do so by all means possible. The challenge is immense, and so are the satisfactions that come from helping countries anxious to find ways of improving the stability and quantity of production from their rangelands. 